\title{
Pyoderma gangrenosum: combination therapy with excellent results in a patient with underlying hepatitis C
}

\author{
Alfredo lardino, Orlando Garner, Yasir Ahmed, Kalpana Bhairavarasu
}

Department of Internal

Medicine, Texas Tech University at the Permian Basin, Odessa,

Texas, USA

\section{Correspondence to}

Dr Alfredo lardino,

alfredo.iardino@ttuhsc.edu

Accepted 3 November 2017

\section{DESCRIPTION}

Pyoderma gangrenosum (PG) is defined as a neutrophilic dermatosis, not related to any infections or gangrenous causes. ${ }^{1}$ It usually appears with an underlying systemic disease. We report a 55-year-old man who presented with painful bilateral skin lesions on legs with no associated constitutional symptoms. Patient had a history of untreated hepatitis $C$ infection with negative cryoglobulinaemia screen. Surgical debridement was performed in the emergency department, at that time without a diagnosis and a biopsy plus culture of the skin was done which disclosed no evidence of microorganism, vasculitis findings and perivascular lymphoplasmacytic infiltrate. A repeat biopsy showed neutrophilic infiltrate. Clinical and histopathological diagnosis of PG was made and patient was started on intravenous steroids with some improvement, ${ }^{2}$

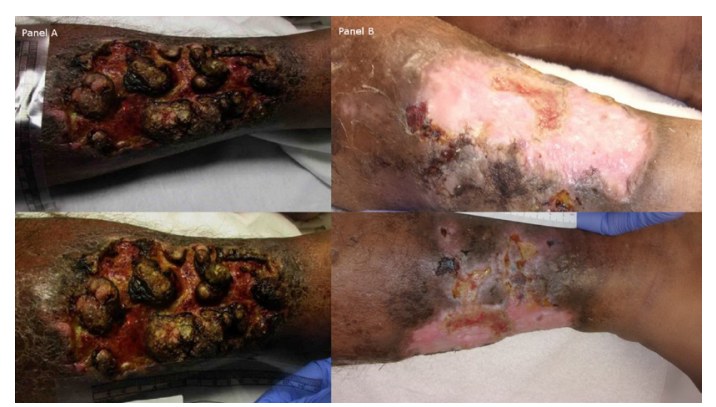

Figure 1 Panel A shows the right lower extremity before treatment, pustular base with hyperkeratotic lesions. Panel B shows right lower extremity after treatment, clear base and resolution of the keratotic lesions.

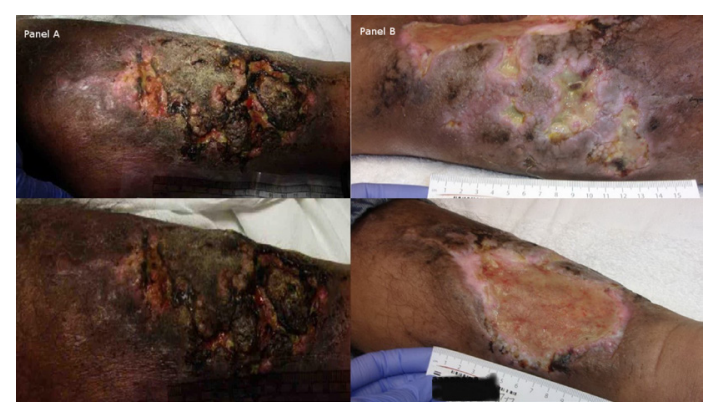

Figure 2 Panel A shows the left lower extremity before treatment, pustular base with hyperkeratotic lesions and crusting, with some areas of haemorrhages. Panel B shows left lower extremity after treatment, clear base and resolution of the keratotic lesions. Upper image of the panel B did show some pustular lesions.

\section{Learning points}

- The diagnosis of pyoderma gangrenosum (PG) has to be based in a combination of both clinical and histopathological features, clinical diagnosis can be made based on suspicions, like in our case where although biopsy was only suggestive of PG and only subsequent biopsy showed the typical neutrophilic infiltrate.

- Treatment should be multidisciplinary, as exemplified by this case managed with intravenous steroids, intravenous immunoglobulin and weekly wound care.

- PG is a rare condition and can sometimes present as a long-standing non-healing ulcers refractory to antibiotic treatment. Awareness is needed in the medical community, so is always present in our differential diagnosis.

followed with clinical deterioration that prompted intravenous immunoglobulin therapy with excellent results. ${ }^{3}$ Patient continues to get weekly wound care and was being seen by infectious disease and rheumatology service. The importance of these images is to remind us that clinical acumen supersedes ancillary tests, since the initial biopsy was only suggestive, and the diagnosis of PG was made based on clinical criteria with combination therapy being adequately started using intravenous steroids, intravenous immunoglobulin and weekly wound care with excellent results (figures 1 and 2).

Contributors Al was responsible for image composition, manuscript writing and editing. $\mathrm{OG}, \mathrm{YA}$ and $\mathrm{KB}$ were involved in the manuscript editing. YA and KB were responsible for the final manuscript approval.

Competing interests None declared.

Patient consent Obtained.

Provenance and peer review Not commissioned; externally peer reviewed.

(C) BMJ Publishing Group Ltd (unless otherwise stated in the text of the article) 2017. All rights reserved. No commercial use is permitted unless otherwise expressly granted.

\section{REFERENCES}

1 Ruocco E, Sangiuliano S, Gravina AG, et al. Pyoderma gangrenosum: an updated review. J Eur Acad Dermatol Venereol 2009;23:1008-17.

2 Ormerod AD, Thomas KS, Craig FE, et al. Comparison of the two most commonly used treatments for pyoderma gangrenosum: results of the STOP GAP randomised controlled trial. BMJ 2015;350:h2958.

3 Song H, Lahood N, Mostaghimi A. Intravenous immunoglobulin as adjunct therapy for refractory pyoderma gangrenosum: systematic review of cases and case series. Br J Dermatol 2017. 
Copyright 2017 BMJ Publishing Group. All rights reserved. For permission to reuse any of this content visit http://group.bmj.com/group/rights-licensing/permissions.

BMJ Case Report Fellows may re-use this article for personal use and teaching without any further permission.

Become a Fellow of BMJ Case Reports today and you can:

- Submit as many cases as you like

- Enjoy fast sympathetic peer review and rapid publication of accepted articles

Access all the published articles

- Re-use any of the published material for personal use and teaching without further permission

For information on Institutional Fellowships contact consortiasales@bmjgroup.com

Visit casereports.bmj.com for more articles like this and to become a Fellow 